\title{
Relatos e ações desenvolvidas por enfermeiras no alcance da equidade em saúde
}

\author{
Reports and actions developed by nurses in the reach of equity in health \\ Informes y acciones desarrollados por las enfermeras para lograr la equidad en la salud
}

\author{
Kerma Márcia de Freitas \\ ORCID: https://orcid.org/0000-0003-3021-4758 \\ Centro Universitário Vale do Salgado, Brasil \\ E-mail: kermamarcia@gmail.com \\ Brenda Pinheiro Evangelista \\ ORCID: https://orcid.org/0000-0002-8830-2681 \\ Universidade Federal do Ceará, Brasil \\ E-mail: brendapinheirro@gmail.com \\ Luiza Jane Eyre de Souza Vieira \\ ORCID: https://orcid.org/0000-0002-5220-027X \\ Universidade de Fortaleza, Brasi \\ E-mail: janeeyre@unifor.br \\ João Paulo Xavier Silva \\ ORCID: https://orcid.org/0000-0003-3082-9373 \\ Centro Universitário Vale do Salgado, Brasil \\ E-mail: pauloxavier@univs.edu.br \\ Breno Pinheiro Evangelista \\ ORCID: https://orcid.org/0000-0001-6881-0980 \\ Faculdade São Francisco da Paraíba, Brasil \\ E-mail: brenopinheiro.2020@gmail.com
}

\begin{abstract}
Resumo
Objetivo: O estudo descreve relatos e ações desenvolvidas por enfermeiras no alcance da equidade em saúde nos serviços de atenção básica. Metodologia: Estudo com abordagem qualitativa, de cunho descritivo, desenvolvido em município do Ceará, Brasil, em 2020. Participaram seis enfermeiras da Estratégia Saúde da Família, que trabalham nas unidades de saúde, todas pós-graduadas em saúde da família/saúde pública. A produção de dados ocorreu por entrevista semiestruturada, analisados pela técnica de análise de conteúdo, modalidade temática, e interpretados à luz da literatura. Resultados: Desse processo, emergiram três categorias temáticas: Aproximações conceituais sobre equidade e iniquidade em saúde; Equidade em saúde na práxis da atenção básica; e, Percepções sobre políticas equitativas e formação acadêmica-profissional. As participantes relacionam equidade a igualdade-justiça e reconhecem ser crucial para efetivar o acesso dos usuários; descrevem ações de enfermagem centradas na avaliação de vulnerabilidades, que promovem o alcance desse princípio. No entanto, destaca-se a importância de ampliarem a interpretação do escopo social que abarca as políticas em saúde, as diretrizes que norteiam o alcance desse princípio. Conclusão: Pondera-se ser imperioso a retomada de diálogos e ações sobre a qualificação das práticas em saúde, decorrente da educação permanente no processo de trabalho na atenção básica.
\end{abstract}

Palavras-chave: Atenção primária à saúde; Equidade em saúde; Sistema Único de Saúde.

\begin{abstract}
Objective: The present study describes reports and actions developed by nurses to achieve health equity in primary care services. Methodology: Qualitative research with a descriptive nature was carried out in a municipality of Ceará State, Brazil, in 2020. The participants were six nurses from the family health strategy working in health units, who had a postgraduation degree in family health/public health. Data collection was performed through semi-structured interviews analyzed using the content analysis technique and thematic modality and interpreted in the light of literature. Results: Three thematic categories emerged from this process: Conceptual approaches on equity and inequity in health; Health equity in the praxis of primary care; and Perceptions on equitable policies and academicprofessional training. The participants relate equity to equality-justice and recognize that it is crucial for effective user access in addition to describing nursing actions centered on the assessment of vulnerabilities, which promote the achievement of this principle. However, it is emphasized the importance of broadening the interpretation of the social scope that encompasses health policies, the guidelines ruling the scope of this principle. Conclusion: Therefore, it is imperative to resume dialogues and actions on the qualification of health practices resulting from continuing education in the work process in primary care.
\end{abstract}

Keywords: Primary health care; Health equity; Unified Health System. 


\begin{abstract}
Resumen
Objetivo: El estudio describe los informes y las acciones desarrolladas por las enfermeras para lograr la equidad em salud en los servicios de atención primaria. Metodologia: Estudio con enfoque cualitativo, de corte descriptivo, desarrollado en el municipio de Ceará, Brasil, en 2020. Participaron seis enfermeras de la estrategia de salud de la familia, que trabajaban en unidades de salud, todas licenciadas en salud de la familia/seguridad pública. La producción de datos de la investigación se produjo a través de entrevistas semiestructuradas, analizadas mediante la técnica de análisis de contenido, de modo temático, e interpretadas a la luz de la literatura. Resultados: De este proceso surgieron tres categorías temáticas: Aproximaciones conceptuales sobre equidad e inequidad en salud; Equidad en salud en la práctica de la atención primaria; y, Percepciones sobre políticas equitativas y formación académico-profesional. Los participantes relacionan la equidad con la igualdad-justicia y la reconocen como crucial para hacer valer el acceso de los usuarios; describen acciones de enfermería centradas en la evaluación de las vulnerabilidades, que promueven la consecución de este principio. Sin embargo, se destaca la importancia de ampliar la interpretación del ámbito social que abarca las políticas de salud, las directrices que guían el alcance de este principio. Conclusión: Se considera imperativo reanudar los diálogos y las acciones sobre la cualificación de las prácticas em la salud, resultantes de la educación permanente en el proceso de trabajo en la atención primaria.
\end{abstract}

Palabras clave: Atención primaria de salud; Equidad en salud; Sistema Único de Salud.

\title{
1. Introdução
}

Em sua configuração, o Sistema Único de Saúde (SUS) pode ser entendido como um núcleo comum e único, que concentra princípios doutrinários e organizativos. Embora tenha alcançado um progresso na melhoria dos indicadores em saúde da população brasileira, desafios persistem quanto a implementação do arcabouço epistêmico e operacional do SUS. Nessa ótica, princípios e diretrizes ainda não foram incorporados em sua totalidade, a exemplo o princípio da equidade em saúde, responsável pela promoção da justiça social (Granja et al., 2013; Silva, Silveira, 2020).

O princípio da Equidade integra o eixo estruturante e articulador do SUS, junto a Universalidade, Integralidade e Controle Social. Nota-se na literatura que o termo é polissêmico e assume interpretações determinadas pela construção histórica, política e social. Na contemporaneidade, a conceituação formulada por Whitehead (1992) enfatiza que a equidade envolve, idealmente, o fato de que todos devem alcançar o melhor potencial de saúde, conduzidos por oportunidades justas (Fiorati et al., 2016; Granja et al.; 2013, Silva, Oliveira, 2020).

O princípio da equidade em saúde associa-se aos direitos das minorias e adentra no espaço público da cidadania, fortalecendo o significado atribuído à diferença. Dessa forma, o ideal da equidade em saúde distancia-se do sentido meramente igualitário no direito e no acesso a esses serviços. A proposta da equidade como um paradigma da justiça distributiva ganhou relevância nas políticas públicas sem, no entanto, acompanhar discussões teóricas acerca deste conceito (Backx, 2005).

$\mathrm{O}$ acesso aos cuidados em saúde é um conceito multidimensional influenciado por diversos fatores. Por isso deve ser analisado por meio da disponibilidade, que trata de obter atenção necessária ao usuário e a sua família; da comodidade, que agrega o tempo de espera para o atendimento, à conveniência de horários, à forma de agendamento, à facilidade de contato com os profissionais, ambiência confortável para o atendimento, entre outros requisitos; e, da aceitabilidade, conexa à satisfação dos usuários quanto à localização, à estrutura física do serviço, ao tipo de atendimento prestado; e, relacionada, também, à aceitação dos usuários quanto aos profissionais responsáveis pelo atendimento (Brasil, 2010).

A Atenção Primária à Saúde (APS) enquanto ordenadora e coordenadora do cuidado, porta de entrada preferencial para o sistema de saúde, deve ser responsável pelo acesso, coordenação do fluxo para outros níveis de atenção, valorização da equidade e a efetivação das ações nos serviços de saúde. Assim, a equidade se traduz em igualdade no acesso ao escopo desses serviços, priorizando populações vulneráveis e considerando as desigualdades oriundas da organização social, inscrita nas políticas neoliberais (Starfield, 2002; Vasconcelos \& Pashe, 2012).

Na última década, o Brasil avança no enfrentamento das desigualdades nos serviços de saúde. Este avanço se deu, principalmente, por meio da formulação e implementação de políticas e programas para a promoção da equidade direcionadas a populações que continuam à margem da simetria de oportunidades que impulsionam melhorias na qualidade de vida. Pode-se 
destacar os idosos, crianças, negros, mulheres em situação de violência, população negra, quilombolas, pessoas que habitam no campo e nas florestas, na zona rural, assim como o movimento político e social que defende a diversidade, mais representatividade e direitos, no sentido de mitigar as barreiras de acesso.

Nesse contexto, o Ministério da Saúde (MS) elegeu como uma das prioridades do governo federal reduzir as desigualdades sociais e iniquidades em saúde, assumindo que "[...] à ampliação e qualificação do acesso universal, em tempo oportuno, contribuindo para a melhoria das condições de saúde, promoção da equidade e da qualidade de vida dos brasileiros." Esta afirmação consta nas diretrizes do Plano Plurianual (PPA) 2016-2019 (Brasil, 2016, p. 03).

No Brasil, os serviços de atenção básica assumem a Estratégia Saúde da Família (ESF), como cenário propício para mitigar as desigualdades e empreender a reorganização da atenção básica no país, de acordo com os preceitos do SUS, fortalecendo o acesso universal, equânime, intersetorial e a organização do processo de trabalho. Nesse contexto, destaca-se a equipe de enfermagem, na qual os enfermeiros, no exercício da liderança, tornam-se agentes transformadores de realidades. Esses profissionais respondem pela condução de ações promotoras de saúde de modo equânime, adentrando na diversidade dos territórios brasileiros (Granja et al., 2013).

Para isto, é importante apropriar-se das diretrizes estabelecidas nas políticas públicas que apresentem demarcações fomentadoras de equidade em saúde para, a partir de então, prover mudanças nas suas ações e direcionar as suas práticas ao alcance desse princípio na atenção básica (Chaves et al., 2011). É notória que essa apropriação vem sendo comprometida, tendo em vista a dinâmica com que as diretrizes, resoluções e portarias são publicadas e alteradas, considerando o tempo necessário para maturação e acomodação à realidade local.

Nessa conjuntura, indaga-se qual seria a compreensão e ações desenvolvidas por enfermeiros, no decorrer de suas práticas na atenção básica, como possibilidade da melhoria do acesso e equidade em saúde? Acredita-se que a realização das ações desses profissionais nos territórios em que estão inseridos são ferramentas potentes para mitigar as perenes assimetrias na efetivação dos princípios do SUS. Ademais, a compreensão da realidade estudada é um dos caminhos para aprimorar a assistência conferida nos serviços de atenção a grupos considerados vulneráveis.

Frente ao exposto, o estudo descreve relatos e ações desenvolvidas por enfermeiras no alcance da equidade em saúde, realizadas nos serviços de atenção básica.

\section{Metodologia}

O estudo elege a abordagem qualitativa, cuja produção do conhecimento busca se aproximar de realidades e temas complexos, permeados de subjetividades, vivências, experiências e significados atribuídos. Nessa construção, a lógica do pesquisador como fonte do cotidiano e das experiências captadas possibilita o construto da subjetividade humana (Minayo, 2014). Com natureza descritiva, o estudo viabiliza o entendimento que o profissional enfermeiro atribui ao princípio da equidade e de que forma o aplica no decorrer de sua prática.

Desse modo, por meio de entrevista semiestruturada com itens de características sociodemográficas e questões direcionadas ao significado da equidade em saúde e seus desdobramentos, a pesquisa foi desenvolvida em um município do Ceará, localizado na região Centro-Sul do estado, no período de fevereiro/2020 a janeiro/2021.

Participaram do estudo seis enfermeiras lotadas nas Unidades Básicas de Saúde, situadas na zona urbana. Os critérios de elegibilidade para participação consistiram em: enfermeiras atuantes na ESF; com vínculo profissional no serviço há pelo menos três meses; e, aceitar participar, espontaneamente. Como critérios de exclusão: estar afastada do trabalho por licença, férias ou outro motivo de caráter laboral; e, recusar a participação.

Vale destacar que oito enfermeiras trabalham na zona urbana e receberam o convite para a participação do estudo, no entanto, duas encontravam-se de licenças. Desse modo, a amostragem foi constituída pela totalidade das enfermeiras que 
atenderam aos critérios de elegibilidade.

Para a coleta dos dados, seguiu-se as etapas: contato prévio com as enfermeiras; convite para participarem da pesquisa; esclarecimento sobre a realização da entrevista na modalidade remota; explicações sobre a segurança e sigilo da ferramenta WhatsApp; envio antecipado do Termo de Consentimento Livre e Esclarecido (TCLE) para sua confirmação; após esclarecimentos, realizou-se agendamento com respeito à disponibilidade/conveniência de cada participante. Deu-se atenção especial para que esses agendamentos não comprometessem os atendimentos nas unidades, assim como garantissem conforto e segurança.

As entrevistas foram realizadas individualmente, com gravação e envio síncrono de áudios, por meio do aplicativo WhatsApp, em dias e horários previamente acordados. Estas tiveram tempo média de 30 minutos cada, posteriormente transcritas na íntegra e, como forma de preservar o anonimato, codificadas no modo alfanumérico (E1, E2... E6).

A análise dos dados se deu através da técnica de Análise de Conteúdo, na modalidade temática (Minayo, 2014), seguindo a trajetória analítica proposta por Gomes (2013). Inicialmente procedeu-se a organização do material, decompondo-o em partes correspondentes as respostas atribuídas as questões norteadoras, constituindo o corpus. Feito essa etapa foram extraídas as ideias centrais de cada fala, identificando as semelhanças e proximidades, que posteriormente foram agregadas e deram origem as categorias temáticas: Aproximações conceituais sobre equidade e iniquidade em saúde; Equidade em saúde na práxis da atenção básica; e, Percepções sobre políticas equitativas e formação acadêmica-profissional. Estas, por sua vez, foram discutidas à luz da literatura sobre o tema, bem como as normativas que subsumem o arcabouço teórico-operacional do SUS.

A pesquisa obedeceu aos critérios expressos nas resoluções 466/12 do Conselho Nacional de Saúde (Brasil, 2013), e as recomendações do ofício circular $\mathrm{N}^{\circ} 2 / 2021$ do Comissão Nacional de Ética em Pesquisa (CONEP) que traz as orientações para procedimentos em pesquisas com qualquer etapa em ambiente virtual (Brasil, 2021) e, foi aprovada pelo Comitê de Ética em Pesquisa do Centro Universitário Doutor Leão Sampaio, mediante o parecer de n. 4.373.938.

\section{Resultados e Discussão}

\subsection{Caracterização dos participantes}

Participaram do presente estudo seis enfermeiras, com faixa etária entre 29 e 52 anos, quatro delas se declararam casadas, uma solteira e uma divorciada, apenas uma não tinha filhos. Quanto a formação e atuação profissional, duas haviam concluído a graduação entre três e seis anos, outras duas entre 17 e 19 anos e, as demais, há mais de 20 anos. Todas eram pósgraduadas, quatro na área da saúde família/saúde pública, uma em enfermagem do trabalho, e outra em terapia intensiva, na saúde do adulto. Destaca-se que uma concluiu curso na pós stricto sensu (mestrado) em saúde da família. Sobre a inserção institucional, duas atuavam na unidade em estudo entre três e seis anos e as outras, há mais de 15 anos; apenas uma não possuía vínculo efetivo de trabalho.

\subsection{Compreensão quanto ao significado de equidade e iniquidade}

Seguindo a proposta da análise de conteúdo, na modalidade temática, a partir das falas foi possível identificar a compreensão das enfermeiras quanto aos significados de equidade e iniquidade e sua aplicabilidade nos serviços de saúde, dando origem às seguintes categorias: Aproximações conceituais sobre equidade e iniquidade em saúde; Equidade em saúde na práxis da atenção básica; e, Percepções sobre políticas equitativas e formação acadêmica-profissional.

\section{Aproximações conceituais sobre equidade e iniquidade em saúde}

A primeira categoria intitulada "Aproximações conceituais sobre equidade e iniquidade em saúde" aborda a 
percepção das enfermeiras acerca da equidade e iniquidades. Identificam-se em algumas falas, descrições que se aproximam de um conceito limitado sobre a díade equidade-iniquidade, utilizando o vocábulo equidade como antônimo de iniquidade. Contudo, relacionam ao conceito de igualdade e justiça e reconhecem que a equidade direcionada a saúde é fundamental, como também correlacionam esse princípio à efetivação do acesso a saúde.

"Equidade é tratar todo mundo igual, e os desiguais de maneira desigual, ou seja, oferecer mais para quem tem menos. Iniquidade a meu ver, não sei nem se estou respondendo direito, mas é o contrário, é desigualdade" (A1)

"Equidade é igualdade de direito e de deveres e senso de justiça. Iniquidade é justamente o contrário de tudo isso." (A3)

"Equidade é tratar as pessoas de quem precisa mais, seja de atenção, assistência e quem precisa menos dá menos e inequidade é trata todo mundo igual sem distinção.” (A4)

Em algum momento, foi possível perceber discursos de ordem pessoal que transmitem indignação e vai ao encontro do modo de "fazer política" no país, fortalecendo o nepotismo que cristalizou, há décadas, o modus operandis dos serviços oferecidos às populações. Esta prática, enraizada na cultura organizacional do setor público e/ou privado, produz efeitos deletérios à construção de uma cidadania-cidadã.

"A Equidade seria prestar um serviço priorizando quem tem mais necessidade, e não priorizar porque tem privilégios, porque é amigo, quem tem real necessidade." (A5)

Ao inscrever a compreensão da equidade no campo e contexto da saúde, as entrevistadas recorrem ao entendimento de equidade, se reportando a ideia de priorizar ações e serviços de saúde a quem mais precisa.

"Eu vejo a equidade exatamente quando a gente leva a saúde a quem tem menos, e o SUS, ele é igual para todo mundo, tanto faz você ter um plano de saúde, ser pobre ou ser rico. Equidade pra mim na saúde é exatamente isso, e sempre oferecendo mais a quem tem menos." (A1)

"Tem como objetivo diminuir as desigualdades nos serviços de saúde." (A2)

"Na hora do próprio acolhimento, dá mais atenção as pessoas que procuram a unidade e que tem mais necessidade. Na hora do agendamento de uma consulta." (A3)

As entrevistadas relacionam ainda a importância de se exercer a equidade considerando todo o processo de trabalho da equipe desde o momento do acolhimento ao atendimento propriamente dito, buscando identificar vulnerabilidades.

"Em relação ao contexto da ESF, pra identificar a necessidade de compreensão da equidade, é justamente do atendimento aos mais necessitados e aos mais humildades (vulneráveis)." (A3)

"No contexto da saúde, a equidade é fazer uma avaliação e reconhecer a necessidade de cada pessoa, tem pessoas que necessitam mais e merecem ter prioridade em questões de atenção à saúde.” (A4)

"Equidade no serviço de saúde, seria fazer uma escuta qualificada, das queixas do paciente e fazer uma triagem 
(acolher), e estabelecer uma frequência de atendimento em virtude da sua necessidade." (A5)

Questionadas quanto a necessidade de compreensão da equidade em saúde, as entrevistadas expressaram a importância de se trabalhar esse conceito a fim de sensibilizar profissionais de saúde que o incorporem no seu processo de trabalho e, os usuários, para que compreendam e colaborem com a dinâmica do trabalho da equipe.

"Tem que compreender para melhor atender, por exemplo, quando eu levo um atendimento ao domicílio eu tô mostrando que aquela pessoa no momento está precisando de mais atenção a quem pode ir para o posto." (A1)

"Com certeza, os funcionários do posto precisam compreender esse princípio, pois eles não entendem, como também a comunidade." (A3)

"...os profissionais de saúde devem ter esse conceito de equidade na mente, porque no momento da triagem (acolhimento) precisa ter esse conceito, na hora de distribuir as fichas a maioria dos profissionais dão prioridade aquelas pessoas que são mais conhecidas, que não dão trabalho, esquecendo do princípio da equidade." (A4)

Encontrou-se também, nas falas, a criação e o fortalecimento de vínculo com a comunidade como uma ferramenta importante para a prática da equidade, a partir do momento em que se conhece o contexto em que o indivíduo está inserido.

"A equidade na atenção primária é essencial, e como a gente acaba criando vinculo, a gente consegue entender melhor o contexto de vida, cultura, na qual o indivíduo está inserido, ficar até mais fácil e colocar em prática esse princípio de equidade na atenção primária." (A5)

“... se for percebido que aquela pessoa necessita de maior atenção, de um atendimento específico, dá mais a quem tem menos, um morador de rua, é diferente de uma pessoa que possui uma casa, tem água encanada, tem estabilidade, fazer um plano especifico para cada pessoa, ser justo e dá mais para quem tem menos." (A6)

Identifica-se a potência da vinculação dessas profissionais ao modo de vida e a proximidade com as assimetrias entre os usuários que estão sob a sua responsabilidade socio sanitária.

\section{Equidade em saúde na práxis da atenção básica}

A segunda categoria denominada "Equidade em saúde na práxis da atenção básica" apresenta as ações de enfermagem voltadas para a promoção da equidade na unidade básica de saúde. Dentre elas foram citadas: atendimento comunitário e educação em saúde realizadas na comunidade, ações que facilitam o acesso, acessibilidade, visitas domiciliares, organização do acolhimento, identificação da demanda e o uso do Protocolo de Manchester para classificação de risco.

"Fazendo atendimentos na comunidade, a gente marca encontro para aferir pressão, glicemia, faz vacina dentro das áreas pra facilitar o acesso, visitas aos idosos, para eles não se deslocarem ao posto. Quando a gente faz a visita a puérpera a gente faz também a promoção a equidade, então a visita domiciliar, educação em saúde na comunidade." (A1)

"Realizo atividade coletiva com os idosos na comunidade, em um local que é mais acessivel para eles, pois a unidade é muito longe e não tem acessibilidade, as ruas tem muitas ladeiras e algumas não tem saneamento. [...] vacinas aos 
clientes da terceira idade e a busca ativa nas crianças e mães que não podem levar as crianças até a unidade." (A3)

“... um exemplo de equidade seria as classificações de risco, dá prioridade a quem mais precisa, mesmo que outra pessoa tenha chegado mais cedo, são as classificações de risco que foram protocoladas nas unidades de saúde é uma forma de trabalhar e reconhecer a equidade, necessita que a pessoa que está precisando mais seja atendida rapidamente." (A6)

Chama-se atenção a análise sobre um leque de vulnerabilidades que a profissional depara em sua práxis, evidenciando o momento das consultas de puericultura para identificar e subsidiar planos de ações que possam reduzir essas iniquidades:

“... acho que vê a prioridade seria o seguinte: eu tenho uma criança desnutrida, a mãe alcoólatra, que sofre violência doméstica, e outra que está dentro dos parâmetros do crescimento e desenvolvimento normais, eu preciso ter mais atenção, ter um contato maior, ter mais retorno muito maior do que a criança que está dentro dos padrões normais."

Desse modo, vê-se a importância da atualização permanente a respeito das políticas e correlatos que implicam em reorientações das ações em saúde no âmbito dos territórios e das singularidades dos coletivos.

\section{Percepções sobre políticas equitativas e formação acadêmica-profissional}

A terceira categoria é denominada de "Percepções sobre políticas públicas e formação acadêmica-profissional" retrata o conhecimento das enfermeiras acerca da existência das políticas públicas voltadas a equidade e ainda como tem sido o processo de educação permanente/continuada desses profissionais voltado para a equidade em saúde.

Percebe-se que o conhecimento desses profissionais é superficial no que concerne as políticas nacionais voltadas a Saúde Integral da População Negra, moradores de rua e saúde integral de lésbicas, gays, bissexuais, travestis e transexuais, tendo apenas citado algumas delas sem mais detalhes sobre.

"Em relação a população negra, aos moradores que vivem na rua, como também a de LGBT. Então são essas políticas que eu mais escuto falar, para diminuir as desigualdades, parar com o racismo e com as desigualdades mesmo, para melhorar o padrão de vida dessas pessoas, que são as que mais sofrem em relação a vulnerabilidade e discriminação." (A1)

"Tem a da saúde da população negra, LGBT e políticas públicas para a população de rua e ciganos. Tem várias. Essa da LGBT é pra orientação sexual, identificação de gênero, trabalhar as condições de saúde de lésbicas, gays, bissexuais e travestis, visando uma redução das desigualdades entre eles." (A3)

"Uma das políticas de equidade, é aquela de atenção aos portadores de necessidade, onde se busca dá acesso ao deficiente." (A4)

Ao serem indagadas sobre formação permanente/continuada, a E4 resgata o SUS compreendendo-o como política inclusiva que acompanha a formação acadêmica-profissional. Faz uma alerta de que uma graduação sem conteúdo sobre o SUS, seria o "mesmo que não conhecer a saúde": 
"A todo momento se estuda SUS, na graduação, nas pós em que eu fiz saúde pública com ênfase em saúde da família, atenção domiciliar, no dia a dia em concurso. [...] mas na graduação não ter uma disciplina sobre o SUS, é o mesmo que não conhecer a saúde." (A4)

Outra indagação feita às entrevistadas foi o processo de formação das enfermeiras, e/ou educação permanente/continuada associada a equidade, ficando clara a necessidade de ampliar discussões sobre a temática, uma vez que as enfermeiras relataram momentos em que a equidade é discutida de forma transversal em algum conteúdo, uma disciplina ou mesmo em uma reunião de rotina.

"Sim, eu acho que em todos os cursos, encontros e em todas as rodas de conversa, reunião com a gestão, é um momento de formação sim sobre a equidade em saúde." (A1)

Acrescentaram que inexistem maiores detalhes ou especificidades sobre o princípio da equidade, capacitações ofertadas sobre a temática no âmbito municipal, ocorrendo, somente, por interesse próprio. Quando questionadas sobre capacitação na temática "equidade em saúde”, das seis entrevistadas, apenas uma enfermeira havia participado.

"Em relação a formação de educação permanente ou continuada por parte da gestão do município a qual eu trabalho, eu não vejo, não existe, nunca existiu nada voltada pra isso, mas além da minha formação acadêmica, em outros momentos por buscas pessoais, pra profissão, eu acabei lendo materiais em que eu adquiri.” (A5)

É visível nesse desabafo a fragilidade de uma educação permanente nessas unidades, na busca por soluções possíveis de superar as barreiras que confrontam minimizar as iniquidades em saúde.

\section{Discussão}

As caraterísticas sociodemográficas e profissionais das participantes do estudo identificam a predominância da mulher, jovem e adulta-jovem, o que reitera o fenômeno da feminização do trabalho em saúde e, em especial entre os profissionais de enfermagem reconhecida por Lopes e Leal (2005) e Matos et al. (2013).

Nos discursos, chama atenção interpretações tênues sobre o significado de equidade e iniquidade descontextualizados, em alguns momentos, dos princípios epistêmicos e operacionais do SUS, como sistema orgânico em contínua atualização, ao considerar que todas são pós-graduadas; a maioria em saúde pública/saúde da família. Nesse ponto há de se destacar a educação permanente como indispensável para reorientar concepções teóricas e as práticas profissionais, com a integração do ensino-serviço (Brasil, 2009).

É consenso nos relatórios da OMS de que as melhorias dos indicadores em saúde, a aplicabilidade dos princípios e diretrizes do SUS, materializados nas ações ancoradas na equidade, predominam em equipes com qualificação profissional e atualizações de modo contínuo (OMS, 2013).

O extenso período de exercício profissional na UBS pressupõe aproximação e estabelecimento de vínculos com a dinâmica do território. Depreende-se que este vínculo é construído entre a profissional enfermeira e as demais categorias que formam a equipe de saúde, extensivo ao usuário e a comunidade. É consenso entre os estudiosos de que o tempo de permanência na mesma unidade constitui-se um ponto positivo nessa relação, uma vez que proporciona o conhecimento da realidade de saúde da comunidade, promove a cooperação mútua através do diálogo, respeito e confiança e, sobretudo, a compreensão do significado das ações e dos serviços prestados e a corresponsabilidade do usuário (Reichert et al., 2016). 
Ao reportar-se a compreensão do significado de equidade e iniquidade é crucial apreender que a atenção à saúde não se limita a tratar doenças. Vai além, ao considerar o contexto no qual a doença se desenvolve e a pessoa vive. Isso porque a saúde do indivíduo é determinada por combinações genética, mas alterada por fatores sociais, físico, comportamentais e culturais aos quais o ser humano está exposto. Neste sentido, as ações de saúde devem estar centradas na pessoa (Starfield, 2002; Quintal \& Antunes, 2020).

O conceito de equidade reflete na existência de adaptações que consideram a especificidade das situações na qual poderia promover injustiça em determinadas vezes. Dessa forma, presume-se que esse termo vem ao encontro com intervenções situacionais mediante cada caso, estruturas, normas e sistemas de leis para a qualidade de vida das pessoas (Campos, 2006).

Nas aproximações e distanciamentos conceituais sobre equidade e iniquidade em saúde, depreende-se que para se alcançar ações equânimes e resolutivas na Rede de Atenção à Saúde (RAS) é imprescindível que o usuário tenha, acima de tudo, o acesso a oferta dessas ações. Este acesso, não se limita transpor barreiras geográficas, financeiras, organizacionais, socioculturais, étnicas e de gênero no cuidado, mas, sobretudo, inscrever-se no conceito de que o acesso inclui a adequação dos profissionais e dos recursos tecnológicos utilizados às necessidades de saúde das pessoas (Travassos \& Martins, 2004).

A resolutividade do acesso aos serviços de saúde preconiza a superação das desigualdades e iniquidades em saúde. Prover a população com orientações sobre as ações e serviços disponíveis, trabalho multisetorial, profissionais aptos a lidar com grupos prioritários é uma trajetória resolutiva centrada na equidade (Barros et al., 2016).

A equidade também se relaciona aos direitos sociais, uma vez que o significado desse termo se aproxima do sentido da igualdade, no qual passa a se confundir com a perspectiva de justiça, em virtude das regras justas existentes e interligadas à vida na sociedade. A sua implementação no que diz respeito à saúde, potencializa os atributos essenciais da APS em diversos aspectos (Starfield, 2002) e repercussões rumo a uma práxis equitativa.

Ainda que as falas expressem compreensão voltada à redução das desigualdades nas ações de saúde, estas perduram no processo de trabalho, seja nas implementações da política, nas alocações de recursos e/ou nas contratualizações. Ademais, manifesta-se pelo excesso de autoridade, por influências políticas originando ingerência acrítica na orientação e reorientação da práxis profissional.

Vale ressaltar que a equidade proporciona um modelo nos serviços de saúde associado aos princípios éticos e favorece a justiça distributiva em saúde, para promover o maior alcance frente a superação de eficiências presentes em diferentes áreas de saúde no Brasil, no qual objetiva corrigir equívocos e promover o alcance de propósitos e qualidade das ações em saúde (Nobre et al., 2015).

Deste modo, é importante salientar que essa assistência deve promover a equidade em todos os níveis de atenção, no sentido de minimizar as dificuldades e desigualdades em saúde, justiça social, na implantação e implementação de políticas públicas existentes que possibilitam reduzir as vulnerabilidades nos territórios (Velosso et al., 2020).

Uma participante aludiu sobre o caráter inclusivo do SUS na oferta das ações e serviços, sem distinção da estratificação social. Como sistema complexo, vai além da prestação de serviços, responsabilidade de articular e coordenar atos que consolidem o modelo de promoção à saúde e prevenção de agravos. Demarca-se no arcabouço operacional o respeito a diversidade regional, mostrando a sua unicidade nos princípios fundantes.

Vale ressaltar, ainda, que os serviços privados quando contratados ou conveniados, integram o SUS em caráter complementar, mediante a insuficiência na disponibilidade de serviços públicos. Portanto, não podendo ser comparado aos planos de saúde de natureza privada nos quais tem ações exclusivamente no campo assistencial (Vasconcelos \& Pashe, 2012).

Contudo, a mercantilização da saúde tem fragilizado a efetivação do direito constitucional à saúde e principalmente à equidade no acesso aos serviços, onde os mais privilegiados usufruem de dupla cobertura e, ainda, da judicialização da saúde 
para acessar tratamento de alto custo comprometendo recursos que poderiam ser utilizados para ofertar serviços aos mais pobres (Giovanella et al, 2018; Vasconcelos \& Pashe, 2012).

O princípio da equidade é considerado como articulador do SUS, no sentido de potencializar o progresso e aplicabilidade das políticas de saúde na APS de forma efetiva e de qualidade. Esse princípio é primordial em todas as dimensões do processo de trabalho da enfermagem para promover a qualidade de vida e promoção da saúde em diferentes contextos sociais (Silva \& Oliveira, 2020).

Neste sentido, a equidade vai além de reduzir as desigualdades nos serviços de saúde, promove sobretudo a construção e o exercício dos direitos e deveres preconizados na Constituição Federal (Brasil, 1988) no capítulo V que apresenta o arcabouço teórico e operacional com os eixos fundantes do SUS.

No contraponto, as demandas que se sobrepõem no cotidiano do trabalho, muitas vezes pode deslocar o pensamento crítico, ou seja, a capacidade da associação teórica ganhando contornos de visibilidade na práxis, ao exemplo de enfatizar o acolhimento, um dos elementos cruciais no alcance da equidade.

Ainda que trilhemos na busca da equidade, há também de se considerar que fenômenos complexos que colocam as pessoas e sociedade expostos às vulnerabilidades, não tem como métrica a estratificação social. Salienta-se como exemplo as violências contra grupos específicos que demarcam todos os níveis do estrato social. Esses eventos mostram-se recorrentes nos territórios e demandam olhares ampliados para acolher as vulnerabilidades e serviços que segregam a atenção qualificada e resolutiva.

A vulnerabilidade é multidimensional e envolve uma série de aspectos dos quais alguns estão fora do controle do indivíduo, como: alimentação precária, analfabetismo, má distribuição de renda, desemprego, condições insalubres de trabalho, saneamento básico deficitário, situações de violência permanente, assim como as relações de gênero, raciais e de poder as quais permeiam organizações sociais e as experiências de vida. Aspectos estes que aumentam a exposição do indivíduo ao adoecimento (Ayres, et al, 2009).

As estratégias para a superação das vulnerabilidades em saúde devem abordar a renovação constante das práticas de cuidado em saúde de forma integral e equânime, uma vez que a literatura enfatiza uma contradição nas estratégias de cuidados que não estabelecem a promoção da saúde e ações preventivas para a população em situação de vulnerabilidade. Considerando as necessidades individuais das pessoas, a equidade é um eixo norteador para a garantia do direito universal aos serviços de acordo com as condições de saúde e vulnerabilidades (Dimenstein \& Cirilo Neto, 2020).

A compreensão das dimensões no processo de trabalho em enfermagem preconizado por Sanna (2007) (educar, assistir, pesquisar, participar politicamente e administrar) repercute na prática da equidade. Assim é fundamental a educação permanente em saúde, assistir a comunidade de forma holística, pesquisar sobre a abordagem do tema e participar politicamente do enfrentamento dos desafios evidenciados pela comunidade conforme as diretrizes voltadas à prática com equidade para a satisfação dos usuários. Nesse sentido, destaca-se que a liderança e assistência do enfermeiro devem estabelecer estratégias para a educação permanente da sua equipe, bem como contribuir para a superação das necessidades para o atendimento equânime (Silva \& Oliveira, 2020).

Embora tenha-se uma diversidade de serviços oferecidos pelo SUS, persistem as desigualdades de acesso por segmento da população brasileira, exigindo dessa forma a utilização de medidas de discriminação positiva a exemplo da educação. Dessa forma, participar da construção de políticas de promoção da equidade, poderá levar a prestação de um cuidado sem paternalismo, discriminação ou privilégios. Vale destacar a necessidade de sensibilizar os pares às boas práticas de cuidado equitativo (Silva \& Oliveira, 2020).

Para a prática da equidade é importante o estabelecimento da competência cultural, classificada por Starfield (2002) como um aspecto derivativo que sinaliza alto nível de qualidade da APS, uma vez que permite a identificação das necessidades 
das subpopulações que pode ou não estar evidentes e relacionadas às características étnicas, raciais ou culturais especiais. Além disso, fortalece o vínculo com a comunidade, ferramenta essencial para a promoção da saúde e prevenção de doenças (Ferreira et al., 2019).

Contudo, verifica-se a partir dos resultados que a equidade se esvazia, desaparece diante das barreiras inerentes aos territórios, seja geográfica ou topográfica. Contudo não pode assumir um caráter de inviabilizar o acesso e a realização de ações e funcionamento dos serviços em busca de operacionalizar o princípio da equidade no SUS. E assim indaga-se: como se alcançar a equidade se o acesso de primeiro contato é negado?

Embora tenha-se percebido a ampliação do acesso aos serviços da APS nos últimos anos, este atributo essencial ainda permanece como um nó crítico para o alcance da qualidade dos serviços, sendo condicionado por características organizacionais e geográficas que interferem na entrada do usuário no sistema. Características individuais e dos serviços possibilitam, ou não, utilizá-los e operacionalizar a longitudinalidade do cuidado (Sousa et al., 2020).

É possível identificar nas falas dificuldades no acolhimento e fragmentação da atenção à saúde. Na tentativa de dirimir essas dificuldades o Sistema de Triagem de Manchester (STM) tem sido utilizado a fim de ampliar o acesso de acordo com o princípio da equidade. Contudo, sua utilização na APS tem apresentado ambiguidades e desafios. Se por um lado o STM consegue romper com o atendimento por ordem de chegada e garantir o acesso, por outro tem-se o desconhecimento da população sobre a realização da classificação de risco, a ampliação do tempo de espera e a prioridade dos casos agudos. Além disso, pode fragilizar o acolhimento causando indiferença nos profissionais para os usuários com demandas subjetivas (Moreira et al., 2017).

Importante ressaltar que o Sistema de Triagem de Manchester se deslocou para o território, mas retrata, por demais, a área clínica hospitalar utilizando os protocolos de preservação dos parâmetros vitais, extremamente importante. Para que seja eficaz na APS é necessário que os profissionais tenham conhecimentos, recursos, habilidades e atitudes para saber como se conduzir diante de emergências.

Visando garantir a equidade no acesso aos serviços de saúde o Ministério da Saúde vem instituindo políticas que respaldam os direitos das pessoas que vivem à margem, quais sejam: idosos, crianças, mulheres em situação de violência, população negra, dos quilombolas, pessoal que habita no campo e nas florestas, na zona rural, aumentado assim a visibilidade para essas populações, não se limitando só a elas.

Nesse contexto, são instituídos programa e políticas, uma gama de marcos políticos operacionais, criam-se vazios compreensivos e assistenciais, uma vez que nem os profissionais compreendem a dimensão e importância de efetivar uma política. Dessa forma não existe uma prática efetiva que possa reorientar o modo de trabalhar, o modo de pensar e conduzir tanto a atenção como a gestão em saúde.

Nessa perspectiva torna-se imperiosa a necessidade de incorporar a educação permanente no processo de trabalho a fim de situar os profissionais no contexto dessas políticas, aproximando-os dos inúmeros termos e conceitos específicos dando a noção concreta para que possa contribuir para o alcance da equidade, planejando e executando ações que mitiguem as desigualdades.

A atenção básica possibilita a equidade e integralidade do cuidado e o acesso aos serviços de saúde, sendo a articulação do trabalho multiprofissional um dos caminhos para potencializar os princípios do SUS. A efetivação da equidade possibilita reduzir as desigualdades com a oferta de um cuidado qualificado e baseado em evidências, com resolutividade dos serviços proporcionados pela implementação das políticas públicas e do arcabouço do SUS, de acordo com a necessidade dos usuários.

Nesse sentido, as enfermeiras e demais profissionais de saúde devem conhecer o embasamento teórico e operacional do SUS, bem como apropriar-se dos programas e políticas públicas para a redução das vulnerabilidades em saúde. 


\section{Considerações Finais}

Ao descrever os relatos sobre apreensão e materialização do princípio da equidade em saúde, pondera-se que essa trajetória está em construção. A equidade assume contornos de visibilidade por meio das ações realizadas no escopo dos programas e agendas que integram o processo de trabalho na ESF.

$\mathrm{Na}$ compreensão epistêmica desse princípio, há distanciamentos e aproximações, interpolados pelos cenários de extensão e retração, circunscritos na dinâmica que subjaz as promulgações de políticas, programas, portarias e resoluções que "formatam", criam e recriam barreiras visíveis nos embates políticos, ideológicos, culturais, econômicos e sociais.

No entanto, as enfermeiras descreveram a realização de atividades assistenciais para promover a equidade em saúde, incorporadas no cotidiano dos territórios, porém, é desejável ampliar a análise crítica quanto às políticas públicas que trazem na construção e entremeios, pontos norteadores para mitigar as iniquidades sociais. E nessa articulação, aponta-se a necessidade de apropriar-se dos princípios e de modos operacionais para efetivar a educação permanente sobre a equidade em saúde.

O estudo traz como limitações a participação de uma única categoria profissional, como também o surgimento da pandemia que remodelou a forma de coleta de dados, possibilitando que o participante consultasse sobre a temática, para responder. Desta forma, destaca-se a importância de novos estudos que revisitem a compreensão dos princípios e diretrizes do SUS envolvendo as diversas categorias profissionais e os usuários.

\section{Referências}

Ayres, J. R. C. M., França Júnior, I., Calazans, G. J. \& Saletti Filho, H. C. (2019). O conceito de vulnerabilidade e as práticas de saúde: novas perspectivas e desafios. In Czeresnia, D., Freitas, C. M. (Orgs.). Promoção da saúde - conceitos, desafios, tendências (pp 117-139). Fiocruz.

Backx, S. S. (2005, 23 a 26 de agosto). Equidade, desigualdade e iniquidade em saúde: mote contra o projeto de universalidade. [Apresentação de trabalho]. Anais da II Jornada Internacional de Políticas públicas, http://www.joinpp.ufma.br/jornadas/joinppII/pagina_PGPP /Trabalhos2/Sheila_de_Souza_Backx254.pdf.

Barros, F. P. C., Lopes, J. S., Mendonça, A. V. M. \& Sousa, M. F. (2016) Acesso e equidade nos serviços de saúde: uma revisão estruturada. Saúde Debate 40(110), 264-271. http://dx.doi.org/10.1590/0103-1104201611020.

Brasil. (2021). Ministério da Saúde. Secretaria-Executiva do Conselho Nacional de Saúde. Comissão Nacional de Ética em Pesquisa. Ofício circular N 2/2021/CONEP/SECNS/MS. http://conselho.saude.gov.br/images/Oficio_Circular_2_24fev2021.pdf.

Brasil. (2009). Ministério da Saúde. Secretaria de Gestão do Trabalho e da Educação na Saúde. Departamento de Gestão da Educação em Saúde. Política Nacional de Educação Permanente em Saúde. https://bvsms.saude.gov.br/bvs/publicacoes/politica_nacional_educacao_permanente_saude.pdf.

Brasil. (2010). Ministério da Saúde. Portaria $n^{\circ} 4.279$, de 30 de dezembro de 2010. Estabelece diretrizes para a organização da Rede de Atenção à Saúde no âmbito do SUS. https://bvsms.saude.gov.br/bvs/saudelegis/gm/2010/anexos/anexos_prt4279_30_12_2010.pdf.

Brasil. (2013). Ministério da Saúde. Conselho Nacional de Saúde. Resolução $N^{o} 466$ de 12 de dezembro de 2012. Trata de pesquisas em seres humanos e atualiza a resolução 196. https://conselho.saude.gov.br/resolucoes/2012/Reso466.pdf

Brasil. (1988). Presidência da República. Casa Civil. Constituição da República Federativa do Brasil. Brasília: Supremo Tribunal Federal: Centro Gráfico. http://www.planalto.gov.br/ccivil_03/constituicao/constituicao.htm

Brasil. (2016). Presidência da República. Secretaria Geral. Lei $n^{o}$ 13.397, de 21 de dezembro de 2016. Institui o planejamento governamental e o plano plurianual. http://www.planalto.gov.br/ccivil_03/_ato2015-2018/2016/lei/113249.htm.

Campos, G.W.S. (2006). Reflexões Temáticas sobre Equidade e Saúde: o caso do SUS. Saúde e Sociedade, 15(2),23-33. http://dx.doi.org/10.1590/S010412902006000200004.

Chaves, M. M. N.; Larocca, L. M. \& Peres, A. M. (2011). Enfermagem em saúde coletiva: a construção do conhecimento crítico sobre a realidade de saúde. Rev. esc. Enferm, 45(2), 1701-1704. https://doi.org/10.1590/S0080-62342011000800011.

Dimenstein, M. \& Cirilo Neto, M. (2020). Abordagens conceituais da vulnerabilidade no âmbito da saúde e assistência social. Pesqui. prát. Psicossociais. 15,. 1-17.

Ferreira, M. R. L., Santos, A. A. \& Orfão, N. H. (2019). O vínculo no tratamento da tuberculose na atenção primária à saúde: uma revisão integrativa. Rev Bras Promoç Saúde, v.32. https://doi.org/10.5020/18061230.2019.9540.

Fiorati, R.C., Arcêncio, R.A. \& Souza, L.B. (2016). As iniquidades sociais e o acesso à saúde: desafios para a sociedade, desafios para a enfermagem. Rev. Latino-Am Enfermagem, 24. https://doi.org/10.1590/1518-8345.0945.2687. 
Giovanella, L, Mendoza-Ruiz, A., Pilar, A. C. A., Rosa, M. X., Martins, G. B., Santos, I. S., Barata, D., Vieira, J. M. L., Castro, V. C. G., Faria, P. O. S. \& Machado, C. V. (2018). Sistema universal de saúde e cobertura universal: Desvendando pressupostos e estratégias. Cien Saude Colet, $23(6), 1763$ - 1776. https://doi.org/10.1590/1413-81232018236.05562018.

Gomes, R. Análise e interpretação de dados de pesquisa qualitativa. In: Minayo, M. C. S., Deslandes, S. F. \& Gomes, R. (2013). Pesquisa social: teoria, método e criatividade. (33a ed). Editora Vozes.

Granja, G. F., Zobolli, E. L. C. P. \& Fracolli, L. A. (2013). O discurso dos gestores sobre equidade: um desafio para o SUS. Ciênc saúde colet, 18(12), 3759-3764. https://doi.org/10.1590/S1413-81232013001200032.

Lopes, M. J. M. \& Leal, S. M. C. (2005). A feminização persistente na qualificação profissional da enfermagem brasileira. Cad. Pagu, 24, 105-125. https://doi.org/10.1590/S0104-83332005000100006.

Matos I. B., Toassi, R. F. C., Oliveira, M. C. (2013). Health professions and occupations and feminization process: trends and implications. Athenea Digital. Revista de Pensamiento e Investigación Social, 13(2). https://doi.org/10.5565/rev/athenead/v13n2.1119.

Minayo, M. C. S. (2014). O desafio do conhecimento: pesquisa qualitativa em saúde. (14a ed). HUCITEC.

Moreira, D. A., Tibães, H. B. B., Batista, R. C. R., Cardoso, C. M. L. \& Brito, M. J. M. (2017). O sistema de triagem de manchester na atenção primária à saúde: ambiguidades e desafios relacionados ao acesso. Texto Contexto Enferm, 26(2), 1-8. https://doi.org/10.1590/0104-07072017005970015.

Nobre, A. L. C. S. D., Dias, O. V., Leite, M. T. S., Freitas, D. M. \& Costa, S. M. (2015). Justiça distributiva no serviço de saúde especializado e no acesso a medicamentos. Rev. Bioética, 23(2), 373-378. https://doi.org/10.1590/1983-80422015232076.

Organização Mundial de Saúde (OMS). (2013, 10 a 14 de junho). Declaração de Helsinque: sobre saúde em todas as políticas. In: VIII Conferência internacional sobre promoção da saúde. http://dssbr.org/site/wp-content/uploads/2013/09/8\%C2\%AA-Confer\%C3\%AAncia-Internacional-dePromo\%C3\%A7\%C3\%A3o-da-Sa\%C3\%BAde.pdf.

Quintal, C. \& Antunes, M. (2020). Equity in Usage of Medical Appointments in Portugal: In Sickness and in Health, in Poverty and in Wealth? Acta Med Port, 33(2), 93-100. https://doi.org/10.20344/amp.12278.

Reichert, A. P. S., Rodrigues, P. F., Albuquerque, T. M., Collet, N. \& Minayo, M. C. S. (2016). Vínculo entre enfermeiros e mães de crianças menores de dois anos: percepção de enfermeiros. Ciênc. saúde colet, 21(8), 2375-2382. https://doi.org/10.1590/1413-81232015218.07662016.

Sanna, M. C. (2007). Os processos de trabalho em Enfermagem. Rev Bras Enferm, 60(2), 221 -224. https://doi.org/10.1590/S0034-71672007000200018.

Silva, N. C. \& Oliveira, H. M. (2020). Reflexões sobre a equidade e sua aplicabilidade ao processo de trabalho em enfermagem. Rev. Bras Enferm, 73(3), 1-5. https://doi.org/10.1590/0034-7167-2019-0783.

Sousa, A. I., Santos, L. B. B., Souza, M. H. N., Paixão, T. M. \& Farias, S. N. P. (2020). Evaluation of accessibility to Primary Health Care services in the view perspective of health personnel Rev. enferm. UERJ; 28. https://doi.org/10.12957/reuerj.2020.47069.

Starfield, B. (2002). Atenção primária: equilíbrio entre necessidades de saúde, serviços e tecnologias. UNESCO, Ministério da Saúde.

Travassos, C. \& Martins, M. (2004). Uma revisão sobre os conceitos de acesso e utilização de serviços de saúde. Cad. Saúde Pública, 20(Sup.2), 5190 5198. https://doi.org/10.1590/S0102-311X2004000800014.

Vasconcelos, C. M. \& Pasche, D. F. (2012). O SUS em perspectivas. In: CAMPOS et.al. Tratado de Saúde Coletiva. (2a ed). FIOCRUZ.

Velloso, I. S. C., Pereira, M. S., Salas, A. S. \& Araújo, M. T. (2020). Desafios da enfermagem na promoção de práticas de equidade em saúde: um diálogo entre a enfermagem no Brasil e no Canadá. Rev Min Enferm, 24(12), 1-8. http://www.dx.doi.org/10.5935/1415-2762.20200011.

Whitehead, M. (1992). The concepts and principles of equity and health. International Journal of Health Services, 1(22), 429-445. https://doi.org/10.2190/986L-LHQ6-2VTE-YRRN. 